\title{
COVID-19 and nutriceutical therapies, especially using zinc to supplement antimicrobials
}

\author{
Desley Butters ${ }^{1} \cdot$ Michael Whitehouse $^{2} \mathbb{C}$
}

Received: 8 October 2020 / Accepted: 25 October 2020 / Published online: 16 November 2020

(c) Springer Nature Switzerland AG 2020

\begin{abstract}
The nutritional status of a patient can be critical for the efficacy of other pharmaceuticals, especially organic antibiotics, to treat viral pandemics. There may be political and scientific difficulties in achieving a constructive synergy of nutritional and prescribed allopathic remedies. For adequate treatment, timelines may need to extend well beyond eliminating viral proliferation, e.g., with vaccines, to include the goals of (a) reducing post-viral fatigue, (b) promoting earliest recovery, and (c) future resistance in often poorly nourished patients, e.g., obese (!). Many trace minerals (TM) and vitamins may need to be replenished. This review focusses only upon zinc to illustrate some problems in rectifying these TM deficiencies affecting the balance between continued ill-health ('illth') or regaining optimal physical and mental wellbeing. Ultimately, this is a matter of behaviour, lifestyle, and informed choice(s). See Hetzel and McMichael 1959.
\end{abstract}

Keywords SARS-2 $\cdot$ Hydroxychloroquine $\cdot$ Ivermectin $\cdot$ Transdermal zinc supplements $\cdot$ Drug-nutrient synergy $\cdot$ Post-viral fatigue

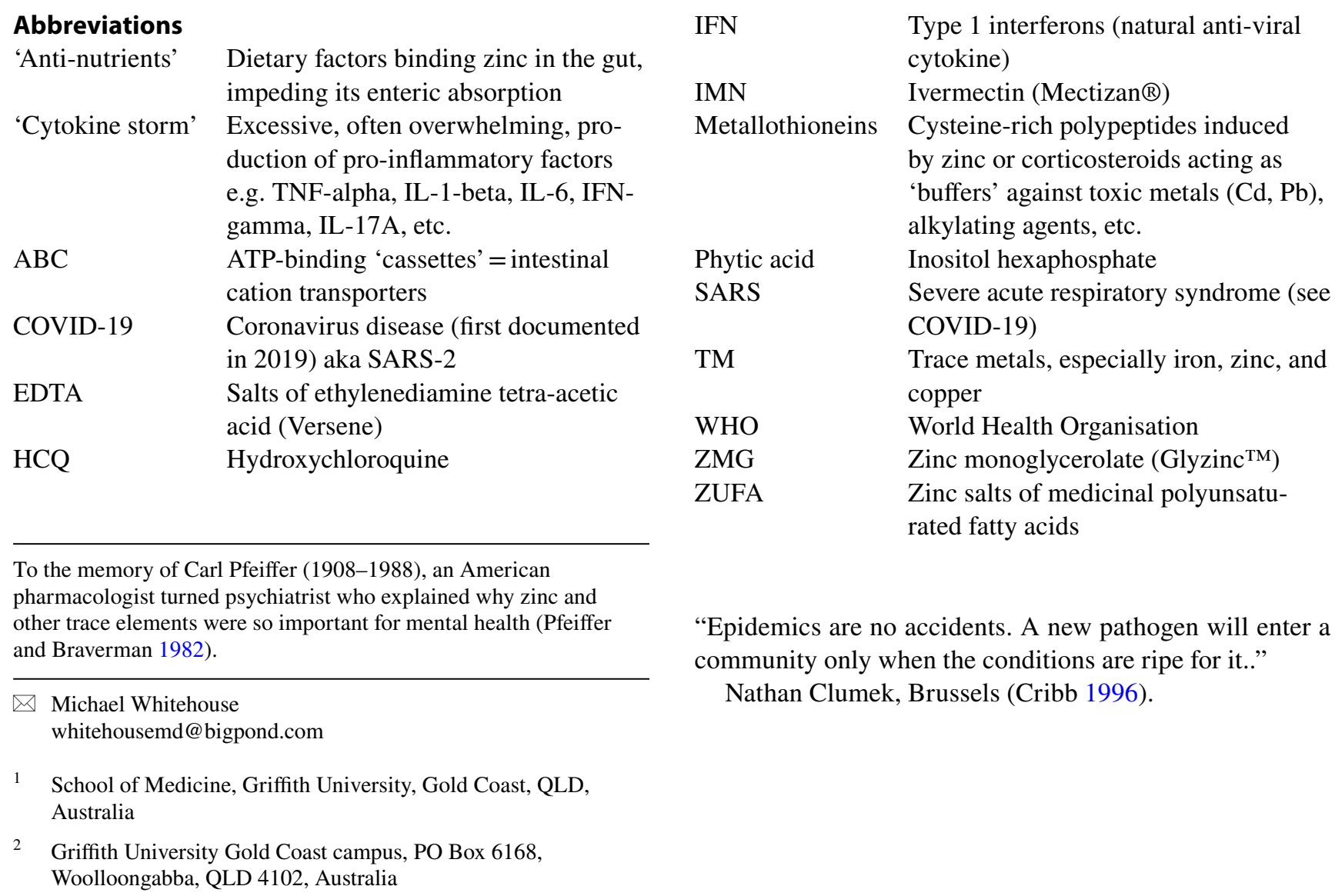


Table 1 Zinc, an adjunct therapy for viral life-threatening infections

Some political and practical difficulties

- Scepticism: It is not in the textbooks or yet been used or advocated by most opinion-leaders of allopathic medicine

- The supernumerary myth: zinc is already available from Western diets, so we do not need to be too concerned if and why it may be insufficient

- The non-inquisitive mindset: some trials have indicated that hydroxychloroquine is not effective, so that is the end of the story, i.e., this 'nonresult' is accepted without criticism or reservation

- Regulatory agencies and drug propagandists tend to discourage polypharmacy involving natural remedies

- Being a natural remedy, zinc cannot be readily patented. The consequence is little or no action by, or support from, the originators of most new medical remedies

- Misinformed mindset ('blindset'). Since the US president, D Trump, extolled hydroxychloroquine, it must be 'wrong', so suggesting its use with zinc is even more unacceptable!!

- Consequent censorship on Twitter, YouTube, Facebook, and elsewhere*, further promoting ignorance of scientific understanding and positive reports

Comments: (i) Once again, political ignorance or following the crowd can trump wisdom (Whitehouse 2020a), even that of D Trump. (ii) The timeless Biblical admonition: "Do not spread false reports" (TNIV 2005) is just as applicable to electronic media as for vocal communication

*Even in the Australian federal parliament in Canberra

\section{Preamble}

This commentary describes some of the problems when practising Integrated Medicine, combining the wisdom of Food Science and Dietetics (FSD) with that of experimental therapeutics. We hear and read much about the latter (it makes money), rather less about the former (FSD) and almost nothing about their synergistic interactions, except when they have adverse effects (fortunately rare)! All that may change as we try to focus on novel approaches for treating the current widespread pandemic presenting as severe acute respiratory syndrome (SARS-2) aka COVID-19. Its lethality often involves a 'cytokine storm' induced as an over-reaction by the host's immune system, overwhelming the patient's resistance. By historical standards, it is one of the lighter pandemics, but still especially dangerous for certain populations: the elderly, the obese and those lacking effective levels of Type 1-interferons.

\section{Therapy}

Since its massive outbreak in 2019 (Chan et al. 2020), a large number of drug candidates have been evaluated as possible inhibitors for this RNA coronavirus. Rather surprisingly, a few of the more promising candidates have not hitherto been classified as antivirals. They include two conventional but quite unrelated anti-infective agents, namely, hydroxychloroquine (HCQ), Plaquenil ${ }^{\mathrm{TM}}$, and Ivermectin (IMN) Mectizan ${ }^{\mathrm{R}}$. When used with a zinc supplement, they may acquire significant anti-viral activity.

HCQ is a synthetic analogue of quinine, available since 1951 to treat malaria, a protozoal disease. It is currently used as a relatively safe anti-rheumatic and to suppress systemic lupus erythematosus (Rainsford et al. 2015). It has been derided on political grounds (Table 1) even rejected, because it does not seem to provide consistent benefits when compared between different trials. This is a very important observation, but needs some answers to ancillary and pertinent questions relating to the status of patients entering clinical trials (age, genetics, obesity, metabolic syndrome and other co-morbidities, drug clearance rates, possible dietary antagonists, etc.) and especially the nutritional and/ or immunological status of the affected patients.

IMN (MK933) is used as an anti-helmintic to prevent 'river blindness', onchocerciasis in West Africa ${ }^{1}$ and Latin America, caused by a filarial nematode (Campbell 1989). It is the second leading cause of blindness, after trachoma. IMN is on the WHO's list of essential medicines.

It also controls COVID-19 infections when used in combination with zinc (Borody and Hazan 2020). Dexamethasone and a number of conventional antibiotics, e.g., doxcycline, clarithromycin, azithromycin, etc., have been considered for trials in COVID-19 clinics. Azithromycin may have particular advantages for use in lung inflammation and congestive conditions because of its unique ability to accumulate in lung parenchyma and mucosa and stimulate interferons (Menzel et al. 2016) [This list will probably grow considerably in the near future.] Their efficacy may also be conditioned by nutritional factors and the patient's immunological status.

\footnotetext{
${ }^{1}$ Where it has been donated free of charge by Merck \& Co, USA for distribution by the Christian Blind Mission and other international aid organisations.
} 
Table 2 Some problems (and queries) about using zinc in crisis medicine

- Recommended daily intake (RDI) for zinc is $12-15 \mathrm{mg}$ taken orally. For crisis medicine, $200 \mathrm{mg} / \mathrm{day}$ has been used in tandem with other antiinfective agents (hydroxychloroquine, ivermectin, etc.)

- Estimated efficiency of intestinal zinc absorption from normal diets may be as low as $20 \%$. This inefficiency is due to inhibition of zinc uptake by a) anti-nutrients,e.g., phytic acid, other polyphosphates, even phosphoric acid (added to soft drinks); b) copper or iron (II) competing with zinc for uptake by intestinal $\mathrm{ABC}$ transporters and c) metal chelators added to processed foods to prevent copper- or iron-induced rancidity, e.g., EDTA; unfortunately also complexing zinc ('collateral damage')

- There is little information about zinc bio-availability when using such 'super-doses'

- For how long can they be used without overtaxing zinc detoxicant/excretion mechanisms or inducing profound copper deficiency?

- Does surplus unabsorbed zinc from such super-doses compromise the symbiotic commensal 'good' bacteria in the bowel?

-What is the effect upon normal zinc-storage mechanisms in bone, or natural sequestration by metallothioneins in the liver?

- Doses with > 150 mg/day oral zinc supplements can be toxic (Chandra 1984; Mindell 1985; Vaughan and Judd 2003;). Lower doses (25$40 \mathrm{mg} /$ day) are therefore advocated (Razzaqe 2020) to reduce potential suppression of beneficial immune responses

- For further discussions of zinc and its importance for human health (for human health treating viral infections), see reviews by Chesapis et al. 2012, Read et al. 2019; Derwand and Scholz 2020; Razzaqe 2020; Skalny et al. 2020; Whitehouse 2020b, amongst others

\section{Zinc status}

This has often been neglected (Table 2) in treating patients or adjusting their therapies, not only for treating COVID19 but many other disorders needing more adequate nutritional support. Zinc deficiency is associated with aging (Prasad 1993) and a wide range of medical disorders $(n \geq 22)$, congenital birth defects $(n \geq 15)$, and degenerative diseases of all age groups (Wallach and Lan 1999). In the context of the COVID-19 pandemic, zinc repletion may be essential for:

i. (Intrinsic) anti-viral activity (Chasapis et al. 2012; Read et al. 2019; Skalny et al. 2020)

ii. Moderating the host's response, the cytokine storm, e.g., inhibiting the biogenesis of TNF-alpha and IL-1 beta (Prasad et al. 2011).

iii. Stimulating early recovery in dual roles of (a) helping combat post-viral depression through some knownand other still unknown - effects on the brain (Pfeiffer and Banks 1982) and the immune system; and (b) repair and restoration of function, especially in the lung; zinc being an essential nutrient for renewed nucleic acid and protein synthesis.

iv. Strengthening host resistance by replenishing depleted zinc reserves in the liver, circulating leukocytes and skeletal tissues.

Chloroquine (and HCQ) may support these activities acting as ionophores assisting (a) zinc distribution to critical responsive sites in the body's tissues and (b) perhaps also withholding zinc from replicating intracellular virus articles. Other zinc-binding molecules, particularly thiols such as $\mathrm{N}$-acetylcysteine (but not D-penicillamine), might be useful adjuncts during intensive therapy.

\section{Obesity}

Many clinicians have observed the high mortality from COVID-19 in their obese patients (Popkin et al. 2020; Rebello et al. 2020; Richardson et al. 2020; SanchisGomar et al. 2020; Lockhart and O'Rahilly 2020). Over $80 \%$ of obese people may compulsively over-eat caused by chronic hunger as their bodies seek essential dietary minerals, lacking in their normal, but impoverished diet. [This is known as 'pica' (Latin for 'magpie') = an abnormal craving for clays, soils from termite mounds (sic) and other sources of essential trace minerals, e.g., iron, zinc, etc.] This geophagy or geopharmacy is extensively practised by impoverished pregnant women in the Third World (Root-Bernstein 1997; Kambunga et al. 2019). It is a testimony to the need for mineral supplements to support health and combat malnutrition.

Zinc supplements may reduce the weight, body mass index, and waist and hip circumference in obese individuals (Khorsanda et al. 2019). From this limited database, two lessons seem to be (1) effective zinc repletion can overcome previous zinc depletion, often chronic before the pandemic but enhanced by rapid viral proliferation; (2) it may take time to adequately restore/renormalise the body's zinc reserves.

A considerable proportion $(\leq 25 \%)$ of COVID-19 patients in recovery phase suffer prolonged post-viral symptoms including mental distress (Garner 2020). Sustained zinc repletion may be needed during this non-lethal second phase of the pandemic.

\section{Other comments}

1. Concerning nutritional status: 
Some facets of this commentary may apply to several anti-inflammatory, antioxidant, and immunostimulant trace elements, e.g., copper, zinc, selenium, other essential nutrients, and many vitamins, e.g., $\mathrm{B}_{6}$. They are all exogenous to the body and must be efficiently ingested from the diet or supplied parenterally.

Three quotes from Carl Pfeiffer writing 40 years ago are still so pertinent today:

- "If only doctors were urged to participate in nutritional guidance, if only they'd become more interested in nutrition...."

- "Orthomolecular medicine (biochemical medicine) is simply the correction of faulty biochemistry, with the right molecules or essential nutrients given at the right time."

- "A preventive program is far more effective than the use of drugs against symptoms." (Pfeiffer and Banks 1982)

2. Concerning early trials of alternative non-vaccine treatments for COVID-19. Some conclusions from certain recent trials of potential therapies have been sharply criticised, their methodologies seeming inadequate and their conclusions questionable (Bramstedt 2020). If the dietary and immunological status of the patients were more fully evaluated before and after the treatments, we might find that personalised corrective therapies (e.g., nutritional, immunostimulant, etc.) are just as important as prescribing any new or rediscovered anti-viral drug.

3. Planned nutrition is now becoming respectable medicine again (BourBour et al. 2020; Polamarasetti and Martirosyan 2020) as it certainly was half a century ago.

4. Final suggestions. Improving the zinc status of COVID19 patients should help to both conquer the infection and bolster their recovery. Other nutrients should also be considered when adopting this health-restoration strategy.

Acknowledgements We are grateful to Professor KD Rainsford for moral support and directing attention to some key references.

\section{Compliance with ethical standards}

Conflict of interest There is no conflict of financial interest.

\section{Appendix}

- An intriguing 'blast from the past' is provided by two observations on the properties of chloroquine (the chronological precursor of hydroxychloroquine): (i) chloroquine manifests many anti-inflammatory effects, disclosed by experimental studies over a wide range of in vitro and in vivo assays (Swingle 1974); (ii) a zincdeficiency disease in chickens presents as a form of polyarthritis, that is corrected by administering chloroquine (Hoekstra 1969). Even 50 years later, poultry scientists are still very concerned about zinc nutrition as 'preventive medicine' (Naz et al. 2016).

The journal Frontiers in Public Health has published some important reviews including treating COVID-19 by dietary changes (Chaari et al. 2020). The companion journal Frontiers in Pharmacology has discussed therapeutic options under investigation (Kaddoura et al. 2020).

\section{References}

BourBour F, Dahka SM, Gholamalizadeh M, Akbari MS, Shadnoush M et al (2020) Nutrients in prevention, treatment, and management of viral infections; special focus on Coronavirus. Arch Physiol Biochem. https://doi.org/10.1080/13813455.2020.1791188

Bramstedt KA (2020) The carnage of substandard research during the COVID-19 pandemic: a call for quality. J Med Ethics. https://doi. org/10.1136/medethics-2020-106494

Brody T, Hazan S (2020) cited by Devine M in the Courier Mail, Brisbane, Australia. Accessed 12 Aug, 2020, p 47

Campbell WC (ed) (1989) Ivermectin and Abamectin. Springer, New York, $\mathrm{p} 363$

Chaari A, Bendriss G, Zakaria D, McVeigh C (2020) Importance of dietary changes during the Coronavirus pandemic: how to upgrade your immune response. Front Public Health. https://doi. org/10.3389/fpubh.2020.00476

Chan JF, Yuan S, Kok KH, To KK, Chu H, Yang J, Xing F, Liu J, Yip CC, Poon RW, Tsoi HW (2020) A familial cluster of pneumonia associated with the 2019 novel coronavirus indicating personto-person transmission: a study of a family cluster. The Lancet 395(10223):514-523

Chandra RK (1984) Excessive intake of zinc impairs immune responses. JAMA 252:1443-1446

Chasapis CT, Spiliopoulou CA, Loutsidou AC, Stefanidou ME (2012) Zinc and human health: an update (Review). Arch Toxicol $86: 521-534$

Cribb J (1996) The white death (did the use of monkeys for medicine cause AIDS?) Sydney Harper Collins Australia p 239

Derwand R, Scholz M (2020) Does zinc supplementation enhance the clinical efficacy of chloroquine/hydroxychloroquine to win today's battle against COVID-19? Med Hypotheses. https://doi. org/10.1016/j.mehy.2020.109815

Garner P (2020) For 7 weeks I have been through a roller coaster of ill health, extreme emotions and utter exhaustion. BMJ Blogs 20200505

Hetzel B, McMichael T (1959) The LS factor: lifestyle and health. Penguin Books Australia Ltd Ringwood Vic. pp 324

Hoekstra WG (1969) Skeletal and skin lesions of zinc-deficient chickens and swine. Am J Clin Nutr 22:1268-1277

Kaddoura M, Allbrahim M, Hijazi G, Soudani N, Audi A et al (2020) COVID-19 therapeutic options under investigation. Front Pharmacol. https://doi.org/10.3389/fphar.2020.01196

Kambunga SN, Candeias C, Hasheela I, Mouri H (2019) Review of the nature of some geophagic materials and their potential health 
effects on pregnant women: some examples from Africa. Environ Geochem Health 41:2949-2975

Khorsandi H, Nikpayam O, Yousefi R, Parandoosh M, Hosseinzadeh N et al (2019) Zinc supplementation improves body weight management, inflammatory biomarkers and insulin resistance in individuals with obesity: a randomized, placebo-controlled, double-blind trial. Diabetol Metab Syndr 11:101. https://doi.org/10.1186/s1309 8-019-0497-8

Lockhart SM, O'Rahilly S (2020) When two pandemics meet: why is obesity associated with increased COVID-19 mortality? Med (NY). https://doi.org/10.1016/j.medj.2020.06.005

Menzel M, Akbarshahi H, Bjerer L, Uller L (2016) Azithromycin induces anti-viral effects in cultured bronchial epithelial cells from COPD patients. Sci Rep 6:28698

Mindell E (1985) The Vitamin Bible. How the right vitamins and nutrients supplements can revolutionise your life, 2nd edn. Arlington Books, London, pp 91-92

Naz S, Idris M, Khalique M, Alhida I (2016) The activity and use of zinc in poultry diets. World's Poultry Sci J 1:1-10

Pfeiffer CC, Banks J (1982) Total nutrition. Granada Publishing Ltd, London, p 162

Pfeiffer CC, Braverman ER (1982) Zinc, the brains and behaviour. Biol Psychiatry 17:513-532

Polamarasetti P, Martirosyan D (2020) Nutrition planning during the COVID-19 pandemic for aging immunity. Bioact Compd Health Dis 3:109-112

Popkin BM, Du S, Green WD, Beck MA, Taghred A, Herbst CH et al (2020) Individuals with obesity and COVID-19: a global perspective on the epidemiology and biological relationships. Obes Rev 21:e13128. https://doi.org/10.1111/obr.13128

Prasad A (1978) Trace elements and iron in human metabolism. Plenum Medical Cook Co., New York, pp 108-109

Prasad AS, Bao B, Beck FW, Sarkar FH (2011) Zinc-suppressed inflammatory cytokines by induction of A20-mediated inhibition of nuclear factor-kappaB. Nutrition 27:816-823

Rainsford KD, Parke AL, Clifford-Rashotte M, Kean WF (2015) Therapy and pharmacological properties of hydroxychloroquine and chloroquine in treatment of systemic lupus erythematosus, rheumatoid arthritis and related diseases. Inflammopharmacology 23:231-269

Razzaque MS (2020) COVID-19 pandemic: can maintaining optimal zinc balance enhance host resistance? Tohoku J Exp Med 251:175-181
Read SA, Obeids S, Ahlenstiel C (2019) The role of zinc in anti-viral immunity. Adv Nutr 10:696-710

Rebello CJ, Kirwan JR, Greenway FL (2020) Obesity, the most common comorbidity in SARS-CoV-2: is leptin the link? Int J Obes 44:1810-1817

Richardson S, Hirsch JS, Narasimhan M et al (2020) Presenting characteristics, comorbidities, and outcomes among 5700 patients hospitalized with COVID-19 in the New York City Area. JAMA 323:2052-2059. https://doi.org/10.1001/jama.2020.6775

Root-Bernstein RS, Root-Bernstein M (1977) Geopharmacy in Honey, mud, maggots and other medical marvels: the science behind folk remedies and old wives' tales. (Chap 5) pp59-71. Boston Houghton Miffin

Sanchis-Gomar F, Lavie CJ, Mehra MR, Henry RM, Lippi G (2020) Obesity and outcomes in COVID-19: when an epidemic and pandemic collide. Mayo Clin Proc 95:1145-1453

Skalny AV, Rink L, Ajsuvakova OP, Aschner M, Gritsenko VA, Alekseenko SI, Svistunov AA, Petrakis D, Spandidos DA, Aaseth J, Tsatsakis A (2020) Zinc and respiratory tract infections: perspectives for covid-19 (Review). Int J Mol Med 46:17-26

Swingle KF (1974) Systems in which activity has been demonstrated for chloroquine. In: Scherrer RA, Whitehouse MW (eds) Antiinflammatory agents, vol II. Academic Press, New York, pp 91-92

TNIV (2005) Holy Bible, today's new international version Exodus $23, \mathrm{v} 1$

Vaughan JG, Judd PA (2003) The Oxford book of health foods. University Press, Oxford, pp 165-166

Wallach J, Lan M (1999) Dead doctors don't lie. Legacy Communications, Franklin Tenn, pp 270-272 378-379

Whitehouse MW (2020a) Some biographical reflections. Inflammopharmacology 28:626-628

Whitehouse MW (2020b) Conditional nutrition (I): concerning zinc as a beneficial but variable regulator of inflammation and experimental arthritis. Inflammopharmacology 28:1401-1406

Publisher's Note Springer Nature remains neutral with regard to jurisdictional claims in published maps and institutional affiliations. 